\title{
Acteoside and Isoacteoside Protect Amyloid $\beta$ Peptide Induced Cytotoxicity, Cognitive Deficit and Neurochemical Disturbances In Vitro and In Vivo
}

\author{
Young-Ji Shiao ${ }^{1}$, Muh-Hwan Su ${ }^{2,3}$, Hang-Ching Lin ${ }^{2,3}$ and Chi-Rei $\mathrm{Wu}^{4, *}$ \\ 1 National Research Institute of Chinese Medicine, Ministry of Health and Welfare, Taipei 11490, Taiwan; \\ yshiao@nricm.edu.tw \\ 2 School of Pharmacy, National Defense Medical Center, Taipei 11490, Taiwan; \\ smh1027@syncorebio.com (M.-H.S.); lhc@sinphar.com.tw (H.-C.L.) \\ 3 Sinphar Pharmaceutical Co., Ltd., Sinphar Group (Taiwan), Research \& Development Center, \\ I-Lan 26944, Taiwan \\ 4 Department of Chinese Pharmaceutical Sciences and Chinese Medicine Resources, College of Pharmacy, \\ China Medical University, Taichung 40402, Taiwan \\ * Correspondence: crw@mail.cmu.edu.tw; Tel.: +886-4-2205-3366 (ext. 5506)
}

Academic Editor: Toshio Morikawa

Received: 1 March 2017; Accepted: 20 April 2017; Published: 24 April 2017

\begin{abstract}
Acteoside and isoacteoside, two phenylethanoid glycosides, coexist in some plants. This study investigates the memory-improving and cytoprotective effects of acteoside and isoacteoside in amyloid $\beta$ peptide 1-42 (A $\beta$ 1-42)-infused rats and A $\beta$ 1-42-treated SH-SY5Y cells. It further elucidates the role of amyloid cascade and central neuronal function in these effects. Acteoside and isoacteoside ameliorated cognitive deficits, decreased amyloid deposition, and reversed central cholinergic dysfunction that were caused by $\mathrm{A} \beta$ 1-42 in rats. Acteoside and isoacteoside further decreased extracellular $A \beta$ 1-40 production and restored the cell viability that was decreased by $A \beta 1-42$ in SH-SY5Y cells. Acteoside and isoacteoside also promoted A $\beta$ 1-40 degradation and inhibited A $\beta$ 1-42 oligomerization in vitro. However, the memory-improving and cytoprotective effects of isoacteoside exceeded those of acteoside. Isoacteoside promoted exploratory behavior and restored cortical and hippocampal dopamine levels, but acteoside did not. We suggest that acteoside and isoacteoside ameliorated the cognitive dysfunction that was caused by A $\beta$ 1-42 by blocking amyloid deposition via preventing amyloid oligomerization, and reversing central neuronal function via counteracting amyloid cytotoxicity.
\end{abstract}

Keywords: acteoside; isoacetoside; amyloid $\beta$ peptide; Morris water maze; acetylcholine; amyloid cascade

\section{Introduction}

Alzheimer's disease (AD), the most epidemic progressive neurodegenerative disorder, is characterized by behavioral disturbances such as cognitive deficits and neuropathological symptoms such as neuronal loss, senile plaques and neurofibrillary tangles [1]. Senile plaque contains fibrils that are compounds of amyloid $\beta$ peptide (A $\beta$ ), which is formed from amyloid precursor protein (APP) via the amyloidogenic pathway [1,2]. When $A \beta$ is oligomerized to amyloid fibrils and deposited in the brain especial entorhinal cortex and hippocampus, it causes cerebral neuronal loss, and particularly the degeneration of cholinergic neuronal circuits in the basal forebrain (BF) (cholinergic dysfunction) [3]. Therefore, recent researchers have suggested potential therapeutic approaches against $A D$ that involve several disease-modifying strategies, such as blocking the cellular production of $A \beta$, preventing $A \beta$ oligomerization, promoting $A \beta$ degradation, and counteracting $A \beta$ cytotoxicity [2]. 
Acteoside and its isomeric phenylethanoid glycoside, isoacteoside, (Figure 1) co-exist in various plants, such as Cistanches spp., Castilleja spp. and Plantago spp. [4,5]. Acteoside has been found to have antioxidative, anti-inflammatory, anti-nociceptive, anti-metastatic, hepatoprotective and cytoprotective activities [6-12]. Reports have shown that acteoside can alleviate acquired learning disability in mice that is induced by scopolamine [13], and reduce cerebral injury in mice that is induced by D-galactose $[14,15]$. Acteoside also shortens the escape latency in the Morris water maze (MWM) and reduces the number of retention errors in the step-down test in D-galactose plus $\mathrm{AlCl}_{3}$-induced mouse senescence model $[16,17]$. Acteoside protects neuronal damage caused by A $\beta$ 25-35 in SH-SY5Y neuroblastoma cells $[10,18]$ and inhibits the aggregation of $A \beta$ 1-42 in vitro [19]. However, few studies have shown the effects of acteoside on $A \beta$ 1-42-induced cognitive dysfunction in vivo and the pharmacological activities of isoacteoside. Therefore, this study investigates the effects of acteoside and isoacteoside on $A \beta$ 1-42-induced behavioral changes following the osmotic intracisternal infusion of $A \beta \quad 1-42$ into the lateral ventricle in rats. A meta-analysis of four behavioral tasks by Myhrer [20], acetylcholinergic and catecholaminergic activities strongly affect learning and memory. A $\beta$ 1-42-infusion causes central acetylcholinergic and catecholaminergic dysfunction, which is closely related to memory deficits [21,22]. Therefore, this study further investigates the role of the central neurotransmitters in the acteoside- or isoacteoside-induced reversal of cognitive dysfunction that is caused by A $\beta$ 1-42 infusion by measuring the levels of central neurotransmitters and the activities of related enzymes. Cognitive dysfunction and neurotransmitter disturbances in AD patients are closely associated with an amyloid cascade that involves amyloid generation, amyloid oligomerization and amyloid cytotoxicity [1,2,22]. The effects of acteoside and isoacteoside on amyloid generation, amyloid oligomerization and amyloid cytotoxicity are investigated in vitro to elucidate their memory-improving effects on A $\beta$ 1-42-induced cognitive dysfunction.


Figure 1. Structures of: (A) acteoside; and (B) isoacteoside.

\section{Results}

\subsection{In Vivo A 1 -42-Infusion Model}

\subsubsection{Effects of Acteoside and Isoacteoside on Behavioral Dysfunction Induced by A $\beta$ 1-42 in Rats}

A $\beta$ 1-42 infusion reduced the index of exploratory behavior, which incorporates time spent in the hole and the number of entries into the hole $(p<0.01, p<0.001)$ (Figure $2 \mathrm{~A}-\mathrm{C})$, but A $\beta$ 1-42 infusion did not alter the movement time, distance or velocity of rats (Figure S1). Acteoside $(2.5 \mathrm{mg} / \mathrm{kg}) \mathrm{or}$ 
isoacteoside $(2.5,5.0 \mathrm{mg} / \mathrm{kg})$ increased the time spent in the hole and the number of entry into the hole of $\mathrm{A} \beta$ 1-42-infused rats $(p<0.01)$ (Figure $2 \mathrm{~A}, \mathrm{~B})$, but only isoacteoside $(2.5,5.0 \mathrm{mg} / \mathrm{kg})$ resorted the index of exploratory behavior $(p<0.05, p<0.01$ ) (Figure $2 \mathrm{C}$ ). Neither acteoside nor isoacteoside at any dosage altered the motor activities of $\mathrm{A} \beta$ 1-42-infused rats (Figure S1).

(A) Entries into holes

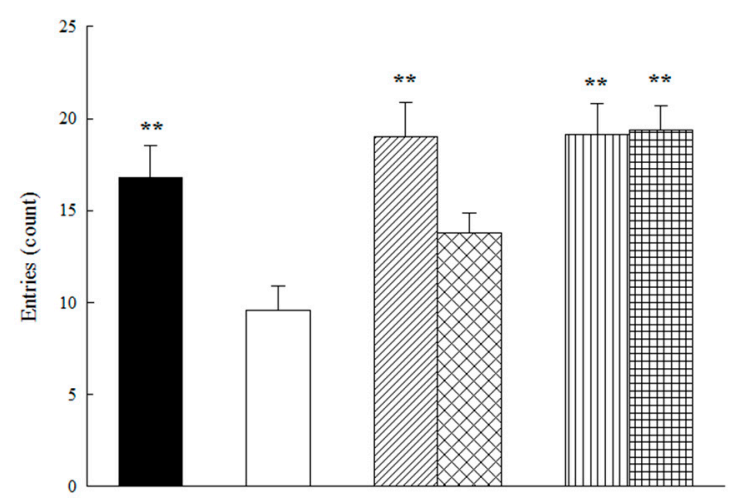

(C) Index of exploratory behavior

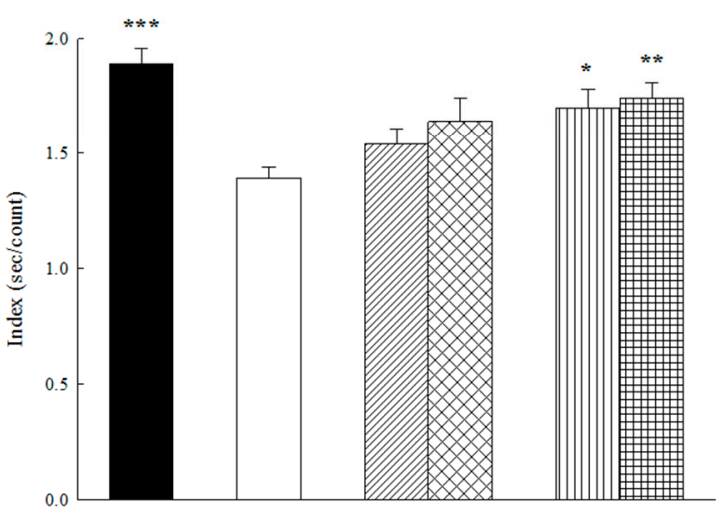

(B) Time spent in holes

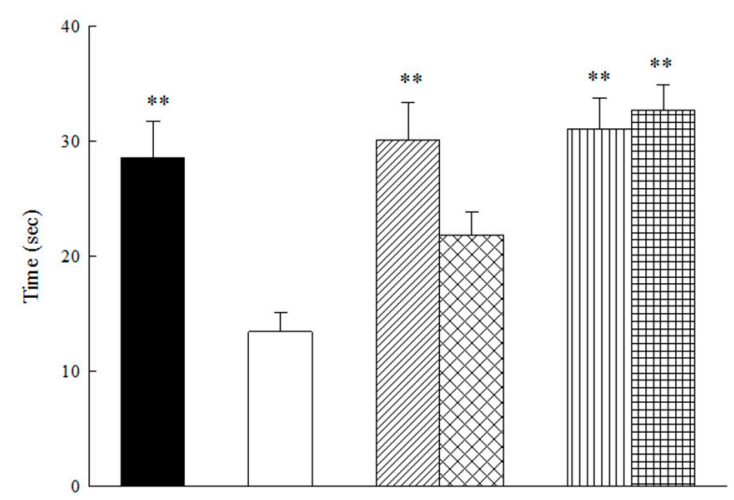

Figure 2. Effects of acteoside or isoacteoside $(2.5,5.0 \mathrm{mg} / \mathrm{kg}$; po) on: (A) the number of entries into holes; and (B) time spent in holes; and (C) index of exploratory behavior in A $\beta$ 1-42-infused rats. Exploratory test was performed on Day 7 following $A \beta$ 1-42 infusion. Acteoside or isoacteoside was continuously administered after $A \beta$ 1-42 infusion until all rats were sacrificed. Columns indicate mean $\pm \operatorname{SEM}(n=12) .{ }^{*} p<0.05,{ }^{* *} p<0.01,{ }^{* * *} p<0.001$ compared with A $\beta$ 1-42-infused rats.

In a passive avoidance test, $A \beta 1-42$ shortened the latency of retention trial relative to the sham group $(p<0.001)$. Acteoside or isoacteoside $(2.5,5.0 \mathrm{mg} / \mathrm{kg})$ prolonged the latency of retention trial in $A \beta 1$ 1-42-infused rats $(p<0.01, p<0.001)$ (Figure 3A). In MWM, the A $\beta 1$-42-infused group had a longer escape latency over eight trials on four training days (from Day 10 to Day 13 following A $\beta$ 1-42 infusion) than the sham group $(p<0.05, p<0.01)$. A $\beta 1-42$ infusion also shortened the time spent in the platform-quadrant from that of the sham group $(p<0.001)$ (Figure 3B,C). Both acteoside $(5.0 \mathrm{mg} / \mathrm{kg})$ and isoacteoside $(2.5,5.0 \mathrm{mg} / \mathrm{kg})$ shortened the increase in escape latency that was caused by $A \beta 1-42$ infusion $(p<0.05, p<0.01)$. Both acteoside and isoacteoside $(2.5,5.0 \mathrm{mg} / \mathrm{kg})$ also prolonged the time spent in the platform-quadrant relative to $A \beta 1$ 1-42-infused group $(p<0.001)$ (Figure 3B,C). However, the sham, A $\beta$ 1-42-infused, acteoside- or isoacteoside-treated groups did not vary in swimming velocity (Figure $3 \mathrm{D}$ ). 


\section{(A) Passive avoidance test}

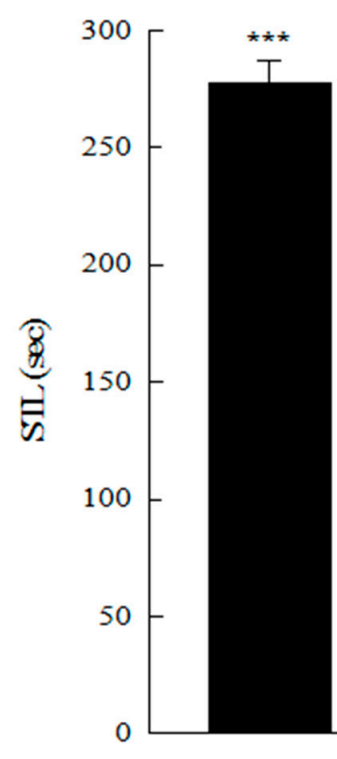

(B) Spatial performance

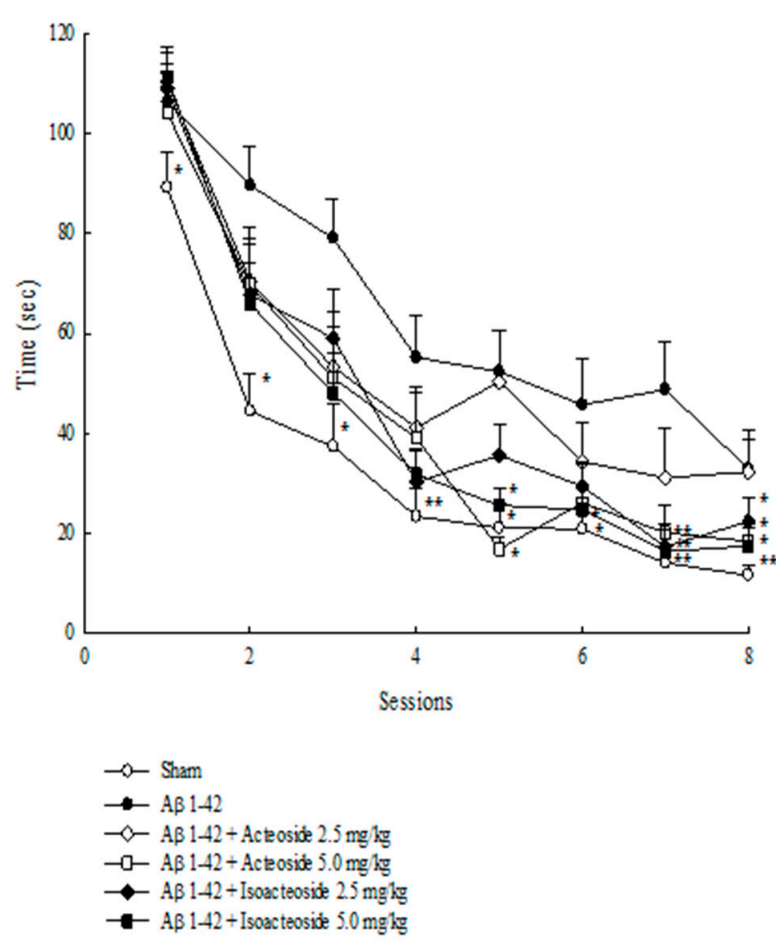

Sham

$A \beta 1-42$

एक्य $\mathrm{A} \beta \mathrm{1}-42+$ Acteoside $2.5 \mathrm{mg} / \mathrm{kg}$ $\mathrm{A \beta} 1-42+$ Acteoside $5.0 \mathrm{mg} / \mathrm{kg}$

피미 A $\mathrm{A}$ 1-42 + Isoacteoside $2.5 \mathrm{mg} / \mathrm{kg}$

A $1-42$ + Isoacteoside $5.0 \mathrm{mg} / \mathrm{kg}$

(C) Probe test

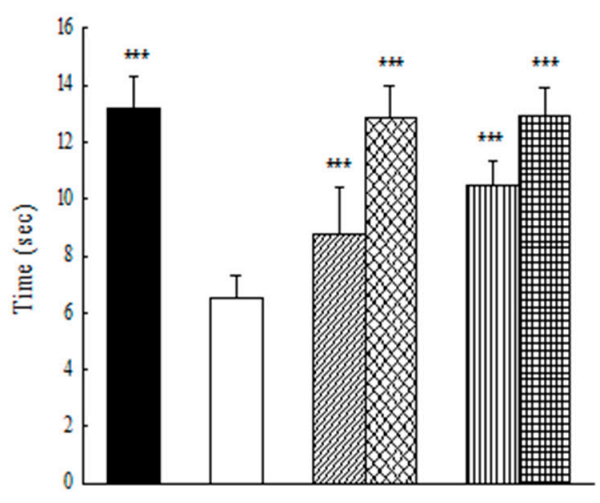

(D) Velocity

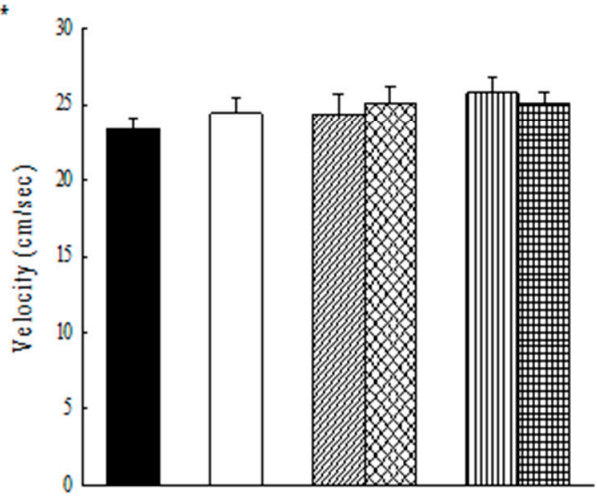

Figure 3. Effects of acteoside or isoacteoside $(2.5,5.0 \mathrm{mg} / \mathrm{kg}$; po) on: (A) step-through latency (STL) of passive avoidance task; (B) spatial performance; (C) probe test; and (D) swimming velocity of MWM in A $\beta$ 1-42-infused rats. Passive avoidance test was performed on Days 8-9 following A $\beta$ 1-42 infusion. Spatial performance and probe test of MWM were performed on Days 10-14 following A $\beta$ 1-42 infusion. Acteoside or isoacteoside was continuously administered after A $\beta$ 1-42 infusion until all rats were sacrificed. Columns indicate mean $\pm \operatorname{SEM}(n=12){ }^{* *} p<0.01,{ }^{* * *} p<0.001$ compared with A $\beta$ 1-42-infused rats. 
2.1.2. Effects of Acteoside and Isoacteoside on Amyloid Deposition and Neurochemical Disturbances Induced by $A \beta 1-42$ in Rats

Figure 4 displays photographs of immunological staining and ratio of $A \beta 1-42$ deposition in the brain. The A $\beta$ 1-42-infused group exhibited a significantly greater ratio of $A \beta 1-42$ deposition in the brain than the sham group $(p<0.01)$. Acteoside $(5.0 \mathrm{mg} / \mathrm{kg})$ or isoacteoside $(2.5,5.0 \mathrm{mg} / \mathrm{kg})$ reduced the ratio of $A \beta 1-42$ deposition in the brain $(p<0.01, p<0.001)$ (Figure $4 \mathrm{G}$ ).

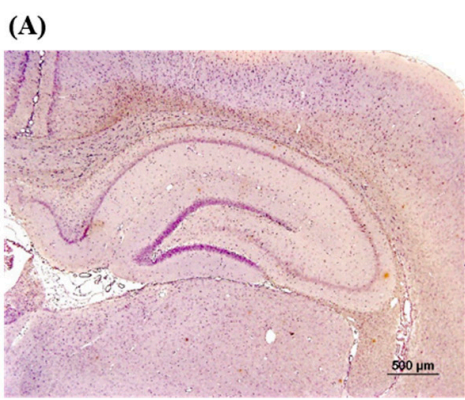

(D)



(G)
(B)

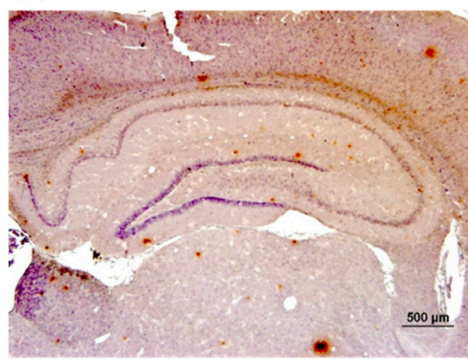

(E)

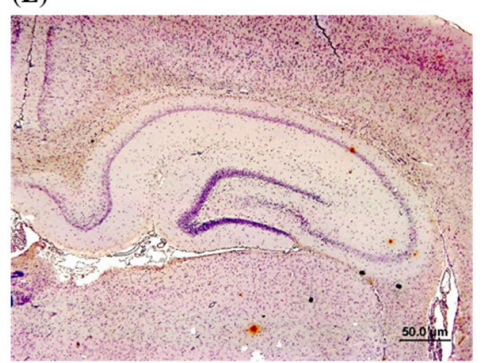

(C)

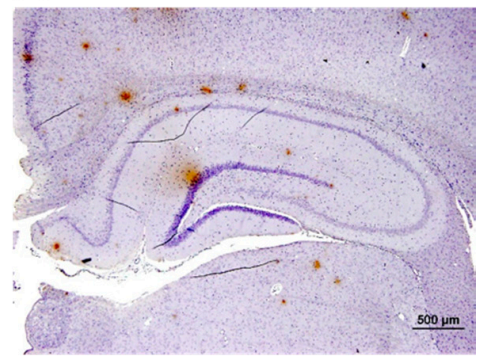

(F)





Figure 4. Effects of acteoside or isoacteoside $(2.5,5.0 \mathrm{mg} / \mathrm{kg}$; po) on $\mathrm{A} \beta$ 1-42 deposition in $\mathrm{A} \beta$ 1-42-infused rats: (A) sham group; (B) A $\beta$ 1-42-infused group; (C) acteoside (2.5 mg/kg)-treated group; (D) acteoside $(5.0 \mathrm{mg} / \mathrm{kg})$-treated group; $(\mathbf{E})$ isoacteoside $(2.5 \mathrm{mg} / \mathrm{kg})$-treated group; and $(\mathbf{F})$ isoacteoside $(5.0 \mathrm{mg} / \mathrm{kg}$ )-treated group; and $(\mathrm{G})$ ratio of amyloid deposition. Acteoside or isoacteoside was continuously administered after $A \beta$ 1-42 infusion until all rats were sacrificed. Columns indicate mean $\pm \operatorname{SEM}(n=6) .{ }^{* *} p<0.01,{ }^{* * *} p<0.001$ compared with A $\beta 1$-42-infused rats.

A $\beta$ 1-42 infusion decreased the levels of cortical and hippocampal acetylcholine (Ach) $(p<0.05$, $p<0.001)$ as well as hippocampal choline (Ch) $(p<0.01)$ (Figure 5A,B). Both acteoside and isoacteoside $(2.5,5.0 \mathrm{mg} / \mathrm{kg})$ reversed the decline in hippocampal Ach levels that were caused by A $\beta$ 1-42 infusion $(p<0.05, p<0.01, p<0.001)$, but only a dose of $5.0 \mathrm{mg} / \mathrm{kg}$ reversed the decrease in cortical Ach levels that was caused by A $\beta 1-42$ infusion $(p<0.05)$ (Figure $5 B$ ). A $\beta$ 1-42 infusion reduced cortical and hippocampal dopamine (DA) levels $(p<0.01, p<0.001)$, but only reduced hippocampal norepinephrine (NE) levels $(p<0.01)$ (Table 1$)$. Only isoacteoside $(2.5,5.0 \mathrm{mg} / \mathrm{kg})$ reversed the decline in hippocampal DA levels that was caused by A $\beta 1-42$ infusion $(p<0.001)$ (Table 1$)$.

$\mathrm{A} \beta$ 1-42 infusion increased cortical and hippocampal acetylcholinesterase (AChE) activities $(p<0.05, p<0.01)$. Both acteoside and isoacteoside $(2.5,5.0 \mathrm{mg} / \mathrm{kg})$ prevented that increase in 
cortical and hippocampal AChE activity that would otherwise have been caused by $A \beta 1-42$ infusion $(p<0.05)$ (Figure 6A). A $\beta$ 1-42 increased cortical monoamine oxidase-A (MAO-A) and MAO-B activities $(p<0.05, p<0.01)$, but reduced hippocampal MAO-A and MAO-B activities in the rats $(p<0.05)$ (Figure 6B-C). Only isoacteoside at $5.0 \mathrm{mg} / \mathrm{kg}$ reversed the decrease in hippocampal MAO-A activity in $A \beta$ 1-42-infused rats $(p<0.01)$ (Figure 6B,C).

(A) Choline levels

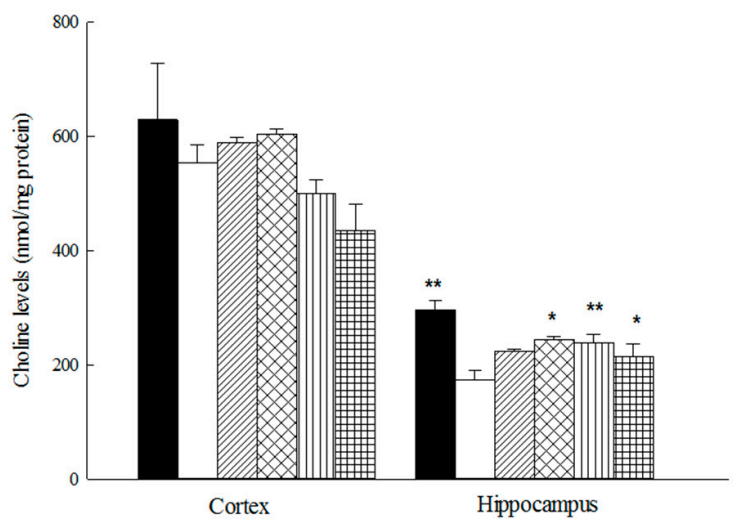

(C) Ratio of $\mathrm{Ch} / \mathrm{ACh}$
(B) Acetylcholine levels

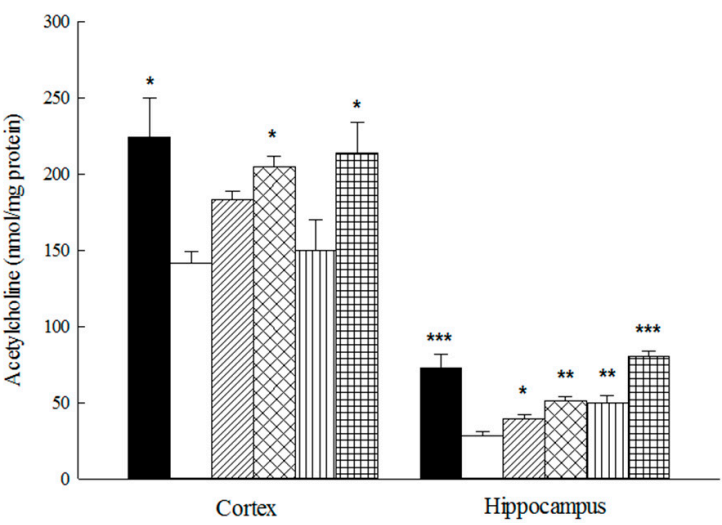

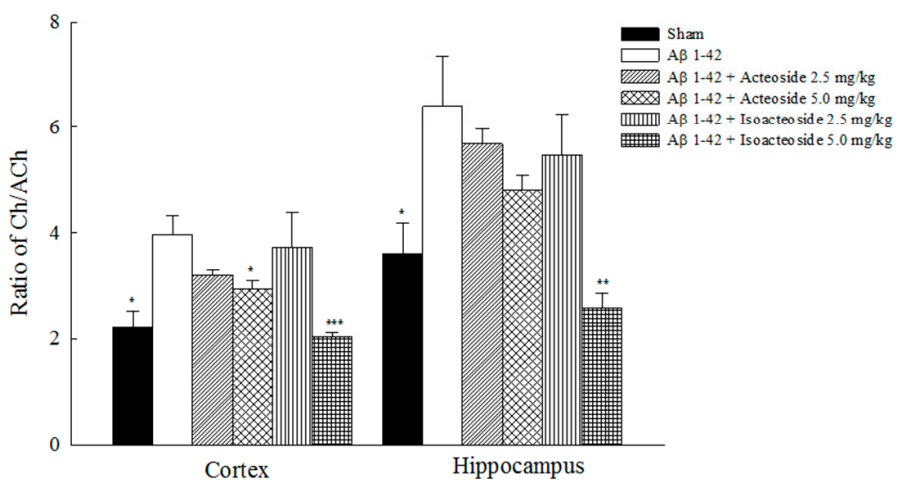

Figure 5. Effects of acteoside or isoacteoside $(2.5,5.0 \mathrm{mg} / \mathrm{kg}$; po) on: (A) choline (Ch) levels; (B) acetylcholine (Ach) levels; and (C) ratio of $\mathrm{Ch}$ to Ach in cortex and hippocampus of A $\beta$ 1-42-infused rats. Acteoside or isoacteoside was continuously administered after $A \beta$ 1-42 infusion until all rats were sacrificed. Columns indicate mean $\pm \operatorname{SEM}(n=6) .{ }^{*} p<0.05,{ }^{* *} p<0.01,{ }^{* * *} p<0.001$ compared with A $\beta$ 1-42-infused rats.

(A) AChE activity

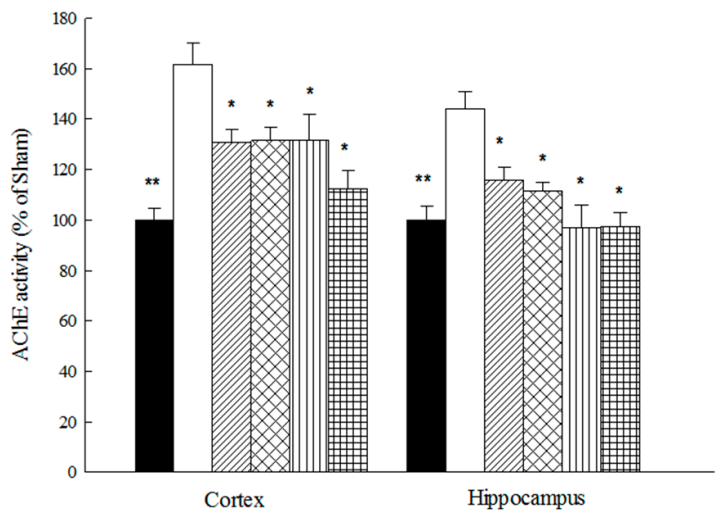

(B) MAO-A activity

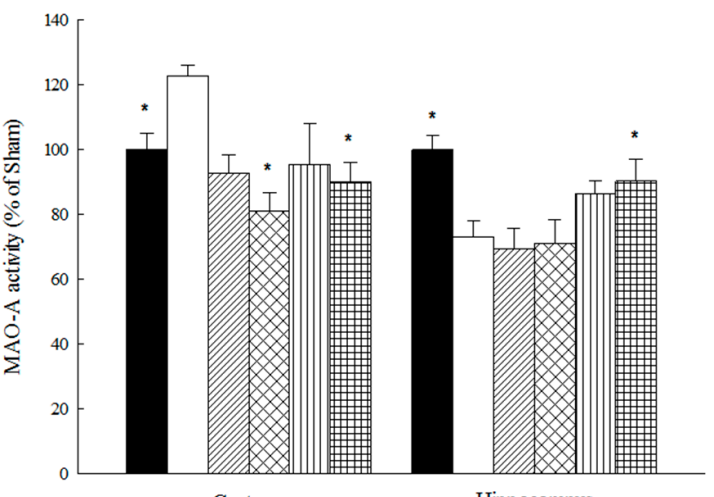

Cortex

Hippocampus

Figure 6. Cont. 
(C) MAO-B activity

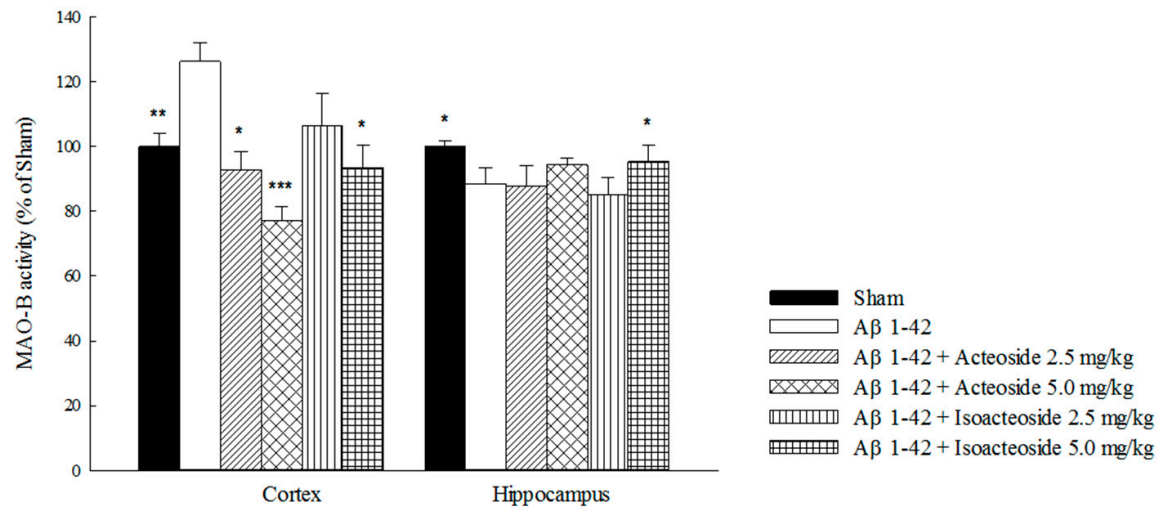

Figure 6. Effects of acteoside or isoacteoside (2.5, $5.0 \mathrm{mg} / \mathrm{kg}$; po) on: (A) AChE; (B) MAO-A; and (C) MAO-B activities in cortex and hippocampus of A $\beta$ 1-42-infused rats. Acteoside or isoacteoside was continuously administered after $A \beta$ 1-42 infusion until all rats were sacrificed. Columns indicate mean $\pm \operatorname{SEM}(n=6) .{ }^{*} p<0.05,{ }^{* *} p<0.01,{ }^{* * *} p<0.001$ compared with A $\beta$ 1-42-infused rats.

Table 1. Effects of acteoside and isoacteoside $(2.5,5.0 \mathrm{mg} / \mathrm{kg}$; po) on the levels of cortical and hippocampal neurotransmitters and their metabolites in A $\beta$ 1-42-infused rats.

\begin{tabular}{|c|c|c|c|c|c|}
\hline \multicolumn{6}{|c|}{ The Levels of Cortical Neurotransmitters and Their Metabolites (ng/g Protein) } \\
\hline- & MHPG & NE & DOPAC & HVA & DA \\
\hline Vehicle & $26.05 \pm 1.11 *$ & $15.63 \pm 0.41$ & $17.13 \pm 0.85 *$ & $3.76 \pm 0.78^{* *}$ & $3.83 \pm 0.16^{* *}$ \\
\hline $\mathrm{A} \beta 1-42$ & $22.87 \pm 0.81$ & $13.61 \pm 1.20$ & $11.97 \pm 0.66$ & $2.90 \pm 0.23$ & $2.18 \pm 0.11$ \\
\hline \multicolumn{6}{|c|}{ Acteoside } \\
\hline $2.5 \mathrm{mg} / \mathrm{kg}$ & $22.40 \pm 1.24$ & $13.08 \pm 1.06$ & $12.91 \pm 0.66$ & $2.87 \pm 0.11$ & $2.26 \pm 0.06$ \\
\hline $5.0 \mathrm{mg} / \mathrm{kg}$ & $23.84 \pm 1.94$ & $12.91 \pm 0.67$ & $13.25 \pm 1.07$ & $2.90 \pm 0.15$ & $2.23 \pm 0.15$ \\
\hline \multicolumn{6}{|c|}{ Isoacteoside } \\
\hline $2.5 \mathrm{mg} / \mathrm{kg}$ & $31.71 \pm 3.21 *$ & $12.60 \pm 1.56$ & $12.53 \pm 3.33$ & $2.91 \pm 0.58$ & $2.67 \pm 0.43$ \\
\hline $5.0 \mathrm{mg} / \mathrm{kg}$ & $34.41 \pm 4.81 *$ & $14.18 \pm 1.01$ & $13.80 \pm 3.03$ & $2.74 \pm 0.69$ & $3.84 \pm 0.47 *$ \\
\hline \multicolumn{6}{|c|}{ The Levels of Hippocampal Neurotransmitters and Their Metabolites (ng/g Protein) } \\
\hline & MHPG & NE & DOPAC & HVA & DA \\
\hline Vehicle & $622.30 \pm 17.58$ & $64.49 \pm 1.65^{* *}$ & $5.90 \pm 0.39$ & $3.60 \pm 0.20$ & $5.41 \pm 0.35^{* * *}$ \\
\hline$A \beta 1-42$ & $620.97 \pm 25.79$ & $51.96 \pm 1.54$ & $5.12 \pm 0.36$ & $3.24 \pm 0.16$ & $0.97 \pm 0.07$ \\
\hline \multicolumn{6}{|c|}{ Acteoside } \\
\hline $2.5 \mathrm{mg} / \mathrm{kg}$ & $641.15 \pm 23.10$ & $53.16 \pm 2.29$ & $5.22 \pm 0.27$ & $3.26 \pm 0.12$ & $1.07 \pm 0.15$ \\
\hline $5.0 \mathrm{mg} / \mathrm{kg}$ & $631.13 \pm 36.81$ & $53.53 \pm 1.83$ & $5.32 \pm 0.14$ & $3.34 \pm 0.10$ & $1.17 \pm 0.13$ \\
\hline \multicolumn{6}{|c|}{ Isoacteoside } \\
\hline $2.5 \mathrm{mg} / \mathrm{kg}$ & $689.99 \pm 79.95$ & $54.01 \pm 6.20$ & $4.98 \pm 1.15$ & $3.68 \pm 0.46$ & $5.28 \pm 0.83^{* * *}$ \\
\hline $5.0 \mathrm{mg} / \mathrm{kg}$ & $574.02 \pm 54.16$ & $45.13 \pm 3.36$ & $4.13 \pm 0.45$ & $3.29 \pm 0.25$ & $5.66 \pm 0.36^{* * *}$ \\
\hline
\end{tabular}

Acteoside or isoacteoside was continuously administered after $A \beta$ 1-42 infusion until all rats were sacrificed. Columns indicate mean $\pm \operatorname{SEM}(n=6) .{ }^{*} p<0.05,{ }^{* *} p<0.01,{ }^{* * *} p<0.001$ compared with A $\beta 1-42$-infused rats.

\subsection{In Vitro Test on Amyloid Cacade}

2.2.1. Effects of Acteoside and Isoacteoside on Neuronal Damage Induced by A $\beta$ 1-42, and Intracellular and Extracellular A $\beta$ 1-40 Levels in SH-SY5Y Cells

Incubation of SH-SY5Y cells with $20 \mu \mathrm{M} \mathrm{A} \beta 1-42$ for $24 \mathrm{~h}$ reduced the cell viability to $52.73 \%$ of that of control cells $(p<0.001)$. Treatment with acteoside $(50 \mu \mathrm{g} / \mathrm{mL})$ or isoacteoside $(50 \mu \mathrm{g} / \mathrm{mL})$ recovered the cell viability that was reduced by A $\beta 1-42(20 \mu \mathrm{M})(p<0.001)$ (Figure 7A). Both acteoside $(50 \mu \mathrm{g} / \mathrm{mL})$ and isoacteoside $(50 \mu \mathrm{g} / \mathrm{mL})$ reduced the extracellular A $\beta$ 1-40 levels in SH-SY5Y cells $(p<0.05, p<0.001)$, but did not alter the intracellular A $\beta$ 1-40 levels (Figure 7B,C). 


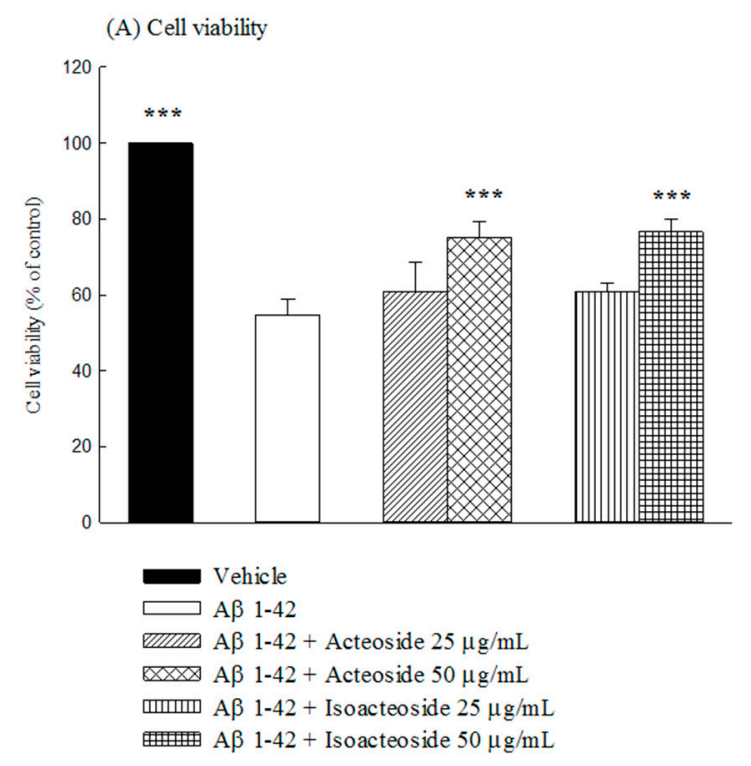

(B) $\mathrm{A} \beta$ 1-40 levels in extracellular culture medium

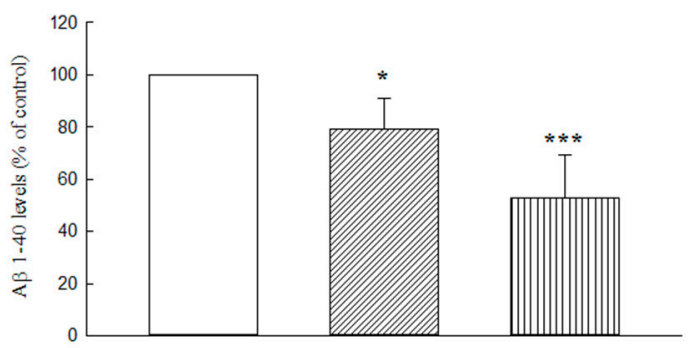

(C) A $1-40$ levels in cell lysate

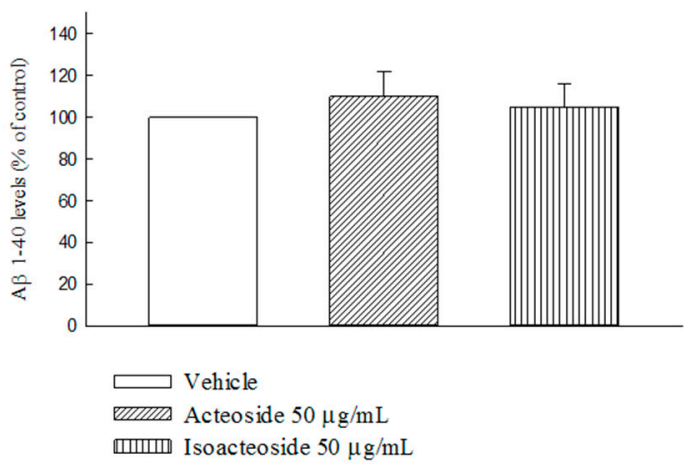

Figure 7. Effects of acteoside or isoacteoside $(25,50 \mu \mathrm{g} / \mathrm{mL})$ on $\mathrm{A} \beta$ 1-42 toxicity, and extracellular and intracellular A $\beta$ 1-40 levels in SH-SY5Y cells: (A) cell viability; (B) A $\beta$ 1-40 levels in extracellular culture medium; and (C) A $\beta$ 1-40 levels in cell lysate. Acteoside or isoacteoside was administered $1 \mathrm{~h}$ before treatment with $\mathrm{A} \beta$ 1-42. Columns indicate mean $\pm \operatorname{SD}(n=4)$. ${ }^{*} p<0.05$, ${ }^{* * *} p<0.001$ compared with (A) A $\beta$ 1-42-treated group or $(\mathbf{B}, \mathbf{C})$ vehicle group.

2.2.2. Effects of Acteoside and Isoacteoside on $A \beta$ 1-40 Degradation and $A \beta$ 1-42 Oligomerization In Vitro

Both acteoside $(50 \mu \mathrm{g} / \mathrm{mL})$ and isoacteoside $(50 \mu \mathrm{g} / \mathrm{mL})$ increased the degradation of added synthetic $A \beta 1-40$ (10 ng) in SH-SY5Y-conditioned cell free medium in vitro $(p<0.05)$ (Figure 8A). Both acteoside $(50 \mu \mathrm{g} / \mathrm{mL})$ and isoacteoside $(50 \mu \mathrm{g} / \mathrm{mL})$ also reduced $\mathrm{A} \beta$ 1-42 oligomerization, as determined from the thioflavin T (ThT) binding fluorescence intensity in vitro $(p<0.001)$ (Figure 8B).

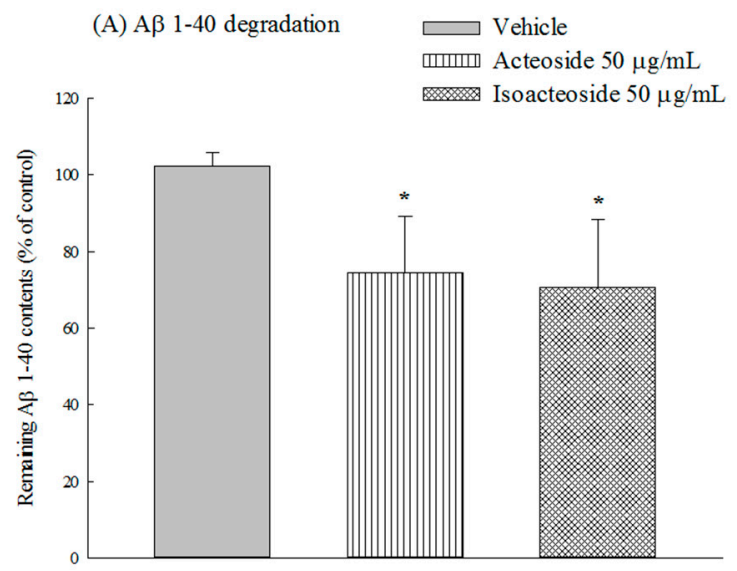

(B) $A \beta$ 1-42 oligomerization

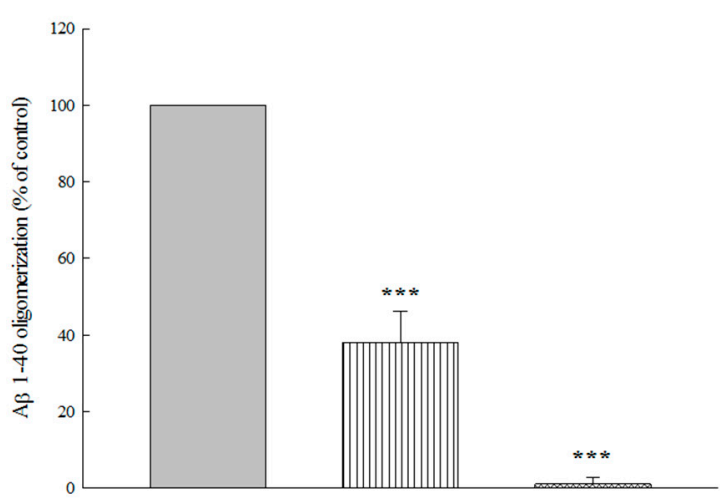

Figure 8. Effects of acteoside or isoacteoside (50 $\mathrm{g} / \mathrm{mL})$ on: (A) A $\beta$ 1-40 degradation; and (B) A $\beta$ 1-42 oligomerization in vitro. Acteoside or isoacteoside was co-cultured with $A \beta$ 1-40 or A $\beta$ 1-42. Columns indicate mean $\pm \mathrm{SD}(n=4) .{ }^{*} p<0.05,{ }^{* * *} p<0.001$ compared with vehicle group. 


\section{Discussion}

Based on AD pathology, $A \beta 1-42$ is the critical protein in $A D$ and intracisternal injection with $A \beta 1-42$ into rats produced memory impairment, morphological changes in the brain, and neuronal degeneration including cholinergic and monoaminergic systems [22,23]. The presented data reveal that intracisternal $A \beta 1-42$ infusion caused behavioral deficits including in the exploratory behavior, passive avoidance response, and spatial performance of MWM in rats. These results are consistent with our previous report and other reports [22-24]. Acteoside at a dose of 2.5-5.0 mg/kg ameliorated the deficits of passive avoidance learning and reference memory that were caused by A $\beta 1-42$, but only a dose of $5.0 \mathrm{mg} / \mathrm{kg}$ ameliorated the impairment of spatial performance. However, no dose of acteoside improved exploratory behavior. These memory-improving effects of acteoside are similar to those identified in other reports, which found that acteoside at $1.0-120 \mathrm{mg} / \mathrm{kg}$ reversed the memory impairment that was induced by scopolamine, D-galactose or D-galactose plus $\mathrm{AlCl}_{3}[13,14,16,17,25]$. This difference between the results obtained herein with those other reports may be related to the given route and duration, and various models. Isoacteoside at $2.5-5.0 \mathrm{mg} / \mathrm{kg}$ exhibited a similar therapeutic potential against $A \beta$ 1-42-induced behavioral dysfunction, but this effect of isoacteoside may differ from that of acteoside because isoacteoside reversed memory impairment partially by promoting exploratory behavior. Thus, we suggest that acteoside and isoacteoside may be potential anti-dementia phenylethanoid glycosides, and that these two stereoisomeric compounds exhibit similar memory-improving potentials but different behavioral-improving patterns against $A \beta$ 1-42-induced behavioral dysfunction.

$\mathrm{AD}$ patients have complex neurochemical disturbances including of the catecholaminergic, cholinergic and glutaminergic neuronal systems [26]. AD patients have higher MAO-B activity than healthy controls, and this increased MAO-B activity may reflect abnormalities in the dopaminergic system [27]. In an AD-like animal model, $A \beta$ 1-42 infusion into the lateral ventricle also caused memory deficits which were closely related to $A \beta$ deposition and a subsequent cascade that caused, for example central cholinergic dysfunction in BF, including a decline in Ach levels and an up-regulation of AChE activity [22,28]. Thus, we further investigated the effects of acteoside and isoacteoside on $\mathrm{A} \beta$-induced pathological changes, including amyloid deposition and neurochemical disturbances in rats. Our present data revealed similar pathological and neurochemical symptoms. Additionally, A $\beta$ 1-42 infusion herein reduced cortical and hippocampal DA levels and hippocampal NE levels. The neurochemical changes were similar to those observed elsewhere [3,21,24]. A $\beta$ 1-42 infusion was also found to cause a differential alteration of cortical and hippocampal MAO activities, mainly by elevating cortical MAO activities and reducing hippocampal MAO activities. Most related investigations have indicated that MAO-B activity was elevated around $\mathrm{A} \beta$ plaques (especially plaque-associated astrocytes), and have suggested the existence of a close positive correlation between MAO-B activity and amyloid plaques in the frontal cortex $[27,29,30]$. However, immunohistochemical studies have demonstrated MAO-B activities reflect disease-specific cellular changes in AD brain, and reduced MAO-B activities in advanced AD patients [31]. Researchers hole differing opinions regarding the alteration of MAO-A activities in AD patient. Recent reports have indicated that the alteration of MAO-A activities in AD patients may be related to presenilin-1 variants. Based on our results and others, we suggest that the alteration of regional MAO-A/B activities following A $\beta$ 1-42 infusion may involve the regional activation of astrocytes around plaques sites and the loss of astrocytes/neurons with the progress of $\mathrm{AD}[27,31]$. $\mathrm{A} \beta$ deposition causes up-regulates $\mathrm{AChE}$ activity around senile plaques, which favors the assembly of $A \beta$ into fibrils, which cause $A \beta$ cytotoxicity and, in particular, cholinergic and dopaminergic dysfunction [3]. Acteoside at $2.5-5.0 \mathrm{mg} / \mathrm{kg}$ reversed hippocampal Ach levels and inhibited the up-regulation of hippocampal AChE activity, but only at $5.0 \mathrm{mg} / \mathrm{kg}$ did it reduce $A \beta$ deposition and reverse the disturbances of cortical Ach levels in $A \beta$ 1-42-infused rats. Isoacteoside at $2.5-5.0 \mathrm{mg} / \mathrm{kg}$ reduced $A \beta$ deposition and restored hippocampal cholinergic and dopaminergic neuronal function, including by blocking $\mathrm{AChE}$ up-regulating activity, but only at $5.0 \mathrm{mg} / \mathrm{kg}$ did it reverse the alteration of cortical and hippocampal MAO activities in A $\beta$ 
1-42-infused rats. Furthermore, acteoside at $5.0 \mathrm{mg} / \mathrm{kg}$ only restored the turnover rate of cortical Ach in A $\beta$ 1-42-infused rats, whereas isoacteoside at $5.0 \mathrm{mg} / \mathrm{kg}$ restored the turnover rate of both cortical and hippocampal Ach (Figure 5C). From these above results, we suggest that the effects of acteoside and isoacteoside against $A \beta$ 1-42-induced cognitive deficit may be related to reducing $A \beta$ deposition, and then leading to a reversal of cortical cholinergic function, including an increase in the cortical Ach levels and a decrease in the Ach utility, by inhibiting AChE activity. Isoacteoside reduces A $\beta$ deposition and Ach utility more than does acteoside. Unlike acteoside, isoacteoside restored cortical and hippocampal DA levels that were decreased by A $\beta$ 1-42 infusion. Some researchers have pointed out that frontal and striatal DA levels are related to exploratory behavior [32-34]. Therefore, the memory-improving effects of isoacteoside may be further related to an improvement in exploratory behavior by the restoration of the dopaminergic function.

According to the amyloid cascade hypothesis, A $\beta$ monomers are generated from APP via amyloidogenic pathway and secreted into the extracellular medium. $A \beta$ monomers aggregated to form progressively larger species such as $\mathrm{A} \beta$ oligomers or fibrils under various physiological conditions, and are then deposited into senile plaques, causing neuronal dysfunction, such as neuronal apoptosis, and a decrease in long-term potentiation [2,3]. The results in this study reveal that acteoside at $50 \mu \mathrm{g} / \mathrm{mL}$ protected SH-SY5Y cells against A $\beta$ 1-42-induced neural damage and inhibited A $\beta$ 1-42 oligomerization, are revealed by ThT fluorescent staining. These results were consistent with earlier reports that acteoside protects A $\beta$ 25-35-induced neural damage in SH-SY5Y and PC12 cells $[10,18]$ and inhibits the fibril formation of $A \beta$ 1-42 in vitro [19]. Acteoside was further found herein to reduce extracellular but not intracellular levels of $A \beta$ 1-40, which was produced by amyloidogenic pathway in SH-SY5Y cells, and promoted $A \beta$ 1-40 degradation in vitro. Hence, acteoside reduced extracellular $A \beta$ 1-40 levels mainly by promoting $A \beta$ 1-40 degradation. Isoacteoside possessed the same pharmacological potential to inhibit the amyloid cascade. The inhibiting by isoacteoside of amyloidogenesis and amyloid oligomerization exceeded that by acteoside. Some reports have indicated that acteoside has cytoprotective effects against $\mathrm{A} \beta 25-35$, glutamate, okadaic acid, and $\mathrm{MPP}^{+}$in vitro, and this effect may be mediated by their antioxidant and antiapoptotic activities by maintaining mitochondrial function and the activities of antioxidative enzymes, decreasing intracellular oxidative stress and Bax/Bcl-2 ratio, and inhibiting caspase- 3 activity $[9,10,18,35,36]$. Other reports have indicated that acteoside protects A $\beta$ 25-35-induced neuronal damage by inducting heme oxygenase- 1 (HO-1) and the activation of transcription factor NF-E2-related factor 2 (Nrf2) by extracellular signal-regulated kinases (ERKs) and phosphatidylinositol 3-kinase/protein kinase B (PI3K/Akt) signaling [18], and restored the expression of neurotrophins including nerve growth factor (NGF), neurotrophin 3 (NT-3), and tropomyosin receptor kinase $\mathrm{A}$ (TrkA) in a D-galactose or D-galactose plus $\mathrm{AlCl}_{3}$-induced mouse senescence model $[15,17]$. NGF and NT-3 exhibited a neuroprotective function with therapeutic potential against neurodegenerative diseases [37]. NGF is synthesized by cortical and hippocampal neurons and retrogradely transported to $\mathrm{BF}$ cholinergic neurons through cholinergic projections that bearing the TrkA and low-affinity p75 neurotrophin receptor [38]. NGF maintains the survival of BF cholinergic neurons and enhances cholinergic neurotransmission through acute neurotransmitter-like and classical trophic mechanisms [39]. Accumulating evidence indicates that NGF improves the survival of cholinergic neurons and reduces cognitive decline in humans with mild AD [40]. Therefore, the linkage of NGF and ERK/Akt-Nrf2 signaling pathway on the memory-improving and cytoprotective effects of acteoside against $A \beta$ 1-42 must be clarified and the cytoprotective mechanism of isoacteoside against $A \beta$-induced neural damage shall be investigated in the future.

\section{Materials and Methods}

\subsection{Animals}

Male Sprague-Dawley rats (300-350 g) were obtained from BioLASCO Taiwan Co., Ltd. They were housed in groups of four, chosen at random, in wire-mesh cages $(39 \mathrm{~cm} \times 26 \mathrm{~cm} \times 21 \mathrm{~cm})$ in a temperature 
$\left(23 \pm 1{ }^{\circ} \mathrm{C}\right)$ and humidity $(60 \%)$ regulated environment with a $12 \mathrm{~h}-12 \mathrm{~h}$ light/dark cycle (light phase: 08:00 to 20:00). The Institutional Animal Care and Use Committee of China Medical University approved the experimental protocol (Protocol No. 99-127-B), and the animals were cared according to the Guiding Principles for the Care and Use of Laboratory Animals. After one week of acclimatization, the rats were used in the experiments that are described below.

\subsection{Drugs}

Acteoside and isoacteoside (with purities of greater than 98\%) were kindly provided by Sinphar Pharmaceutical Co., Ltd. (I-Lan, Taiwan) and freshly dissolved in sterile distilled water. Synthesized human A $\beta$ 1-42 and A $\beta$ 1-40 were purchased from Tocris Bioscience (Ellisville, MO, USA). A $\beta$ 1-42 was freshly dissolved with $35 \%$ acetonitrile $/ 0.1 \%$ trifluoroacetic acid at a concentration of $250 \mathrm{pmol} / \mu \mathrm{L}$ and used to fill into mini-osmotic pump (Alzet 2002; Alza, Palo Alto, CA, USA) in vivo test. A $\beta$ 1-42 and $A \beta 1-40$ were prepared with sterile phosphate buffer saline (PBS) in vitro test.

\subsection{In Vivo Aß 1-42-Infused Model}

An $A \beta$ 1-42-infused rat model was developed by infusing $A \beta$ 1-42 into the cerebral ventricle via a mini-osmotic pump, as described elsewhere [23]. Briefly, rats were anesthetized with phenobarbital (45 mg $/ \mathrm{kg}$, i.p.) and placed in a David Kopf stereotaxic instrument. An infusion cannula was implanted into the left cerebral ventricle (AP-1.5, ML + 0.9, V-3.6 from Bregma), and a continual infusion of A $\beta$ 1-42 (300 pmol/day) was maintained for at least two weeks by attaching an infusion cannula to the mini-osmotic pump. Sham group was infused with $35 \%$ acetonitrile $/ 0.1 \%$ trifluoroacetic acid.

\subsubsection{Schedule of $A \beta$ 1-42-Infused Model}

Surgery, drug treatment, and behavioral tests were scheduled as in our previous report [24]. After implantation, $A \beta 1-42$ infusion began on a day that was designated as Day 0. On the next day (Day 1), the rats were orally administered with vehicle, acteoside or isoacteoside $(2.5,5.0 \mathrm{mg} / \mathrm{kg})$ throughout $A \beta$ 1-42 infusion period. The behavioral tests were carried out from Day 7 to Day 14 after A $\beta$ 1-42 infusion, in the order, locomotor and exploratory tests (Day 7), passive avoidance test (Days 8-9), spatial performance test in MWM (Days 10-13), and probe test in MWM (Day 14). On Day 15 after A $\beta$ 1-42 infusion, the rats were killed $1 \mathrm{~h}$ after their final treatment with acteoside or isoacteoside to measure AChE and MAO activities, levels of neurotransmitters and the metabolites in the brain.

\subsubsection{Behavioral Tests}

The behavioral tests were performed as described in our previous report [23]. On Day 7, locomotor and exploratory tests were simultaneously performed with open-field task (Coulbourn Instruments L.L.C., Holliston, MA, USA). Each rat was observed for $10 \mathrm{~min}$ to record the movement time, distance and velocity (locomotor activity), the number of entries it made into the hole and the time spent (exploratory activity) using TruScan software v 2.07 (Coulbourn Instruments L.L.C.) [24]. On Day 8, the training trial of passive avoidance test was performed with passive avoidance apparatus (Coulbourn Instruments L.L.C.). When the rat entered the dark compartment from the light compartment, the door was closed and an inescapable foot shock ( $0.8 \mathrm{~mA}$ for $2 \mathrm{~s})$ was delivered through the grid floor. On the following day (Day 9), the retention trial of passive avoidance test was conducted. The rat was again placed in the light compartment and the latency was recorded [24]. An upper cut-off time of $300 \mathrm{~s}$ was set. On Days 10-13, the spatial performance in MWM was tested using a black circular stainless pool (with a diameter of $165 \mathrm{~cm}$ and a height of $60 \mathrm{~cm}$ ) that was filled with water at $23 \pm 1^{\circ} \mathrm{C}$ to a depth of $35 \mathrm{~cm}$. Each rat underwent eight training sessions over four consecutive days to find the Plexiglass hidden platform (with a diameter of $10 \mathrm{~cm}$ ) that was submerged $1.0 \mathrm{~cm}$ below the surface of the water. The swim path and escape latency to the platform of a white rat in the black pool were recorded using a video camera and an automated video tracking system device equipped with EthoVision XT software (Noldus Information Technology, Leesburg, VA, USA) [24]. On the following day (Day 14), the probe 
test was performed to measure the reference memory. The platform was removed and the parameters, including the time spent and distance moved in each quadrant while searching for the platform [24].

\subsubsection{Assessment of A $\beta$ 1-42 Deposition, Neurotransmitter Levels, and AChE and MAO Activity in Brain}

The rats in each group were separated into three groups: one for assaying A $\beta$ 1-42 deposition, one for measuring neurotransmitter levels, one for measuring biochemical activities. To assay $A \beta$ 1-42 deposition in the rat brain, the paraffin brain slices of rat were prepared and cut into sections $(10 \mu \mathrm{m})$ using a microtome (Leica 2030 Biocut, Nussloch, Germany). The sections were labeled with a mouse anti-human amyloid $\beta$ protein 17-24 monoclonal antibody (1:300, Dakopatts A/C; Glostrup, Denmark) and developed with $0.05 \%$ diaminobenzidine using a Vectastain kit (Vector Laboratories, Burlingame, CA, USA). The A $\beta$ 1-42 labeled plaques at least 20 fields of each brain section were counted under $40 \times$ magnification using an image analyzer (Leica, Q500MC, Nussloch, Germany). The ratio of $A \beta$ 1-42 deposition was obtained from $A \beta$ 1-42 labeled plaques for each brain section. To measure the neurotransmitter levels, all rats were sacrificed and their brains were separated into cortex and hippocampus, which were placed on ice, according to the protocol of Glowinski and Iversen [41]. The supernatants of the brain tissues were prepared through homogenization, filtration and centrifugation, and then the neurotransmitter (and their metabolite) concentrations of brain supernatants were measured by high-performance liquid chromatography with electrochemical detection (EICOM HTEC-500, Kyoto, Japan). To measure brain AChE and MAO activities, all brains also were cut into cortex and hippocampus, and then the brain supernatants were prepared by homogenization and centrifugation. The brain supernatants and recombinant AChE enzyme were incubated with 5,5'-dithiobis(2-nitrobenzoic acid), and the absorbance at $412 \mathrm{~nm}$ was measured following the addition of acetylthiocholine. AChE activity was expressed as $\mathrm{U} A C h E$ per mg protein. Brain homogenates were incubated with $5 \mathrm{U} / \mathrm{mL}$ horseradish peroxidase, $100 \mu \mathrm{M}$ amplex red, and the substrate ( $5 \mathrm{mM}$ serotonin for MAO-A or $5 \mathrm{mM}$ benzylamine for MAO-B) at $25^{\circ} \mathrm{C}$ for $60 \mathrm{~min}$. The fluorescence intensity was measured, and MAO-A and MAO-B activities were expressed as percentage of the corresponding values for sham rats [24]. The protein content of brain supernatants was quantified using Bio-Rad protein assay kit.

\subsection{In Vitro Test on Amyloid Cacade}

Human SH-SY5Y neuroblastoma cells were cultured in DMEM that was supplemented with $10 \%$ fetal bovine serum, 100 units $/ \mathrm{mL}$ penicillin and $100 \mu \mathrm{g} / \mathrm{mL}$ streptomycin in a water-saturated atmosphere with $5 \% \mathrm{CO}_{2}$ at $37^{\circ} \mathrm{C}$. Experiments were performed $24 \mathrm{~h}$ after the cells were seeded in 96- or 24-well sterile clear-bottom plates. For cytoprotective and amyloidogenic-inhibiting tests, acteoside or isoacteoside $(25,50 \mu \mathrm{g} / \mathrm{mL})$ was dissolved with culture medium. For amyloid degradation and oligomerization, acteoside or isoacteoside $(50 \mu \mathrm{g} / \mathrm{mL})$ was dissolved with sterile phosphate buffer saline.

\subsubsection{Assessment of Cytoprotective Effect in SH-SY5Y Cells}

Acteoside or isoacteoside was treated $1 \mathrm{~h}$ before $A \beta$ 1-42 $(20 \mu \mathrm{M})$. The reduction of 3-[4,5dimethylthiazol-2-yl]-2,5-diphenyl-tetrazolium bromide (MTT) to insoluble formazan was used to evaluate cell viability. Briefly, $24 \mathrm{~h}$ after exposure to $\mathrm{A} \beta$ 1-42 in 96-well plate, the medium was replaced and MTT $(0.5 \mathrm{mg} / \mathrm{mL})$ was added to each well. After incubation for $2 \mathrm{~h}$ at $37^{\circ} \mathrm{C}$, the cells were washed with PBS, and DMSO was added. The absorbance at $570 \mathrm{~nm}$ was measured using an ELISA reader. Cell viability was expressed as a percentage of corresponding value for untreated cells, which served as the control group (designated $100 \%$ viable). Each of four independent experiments was performed in triplicate. 


\subsubsection{Assessment of Intracellular and Extracellular A $\beta$ 1-40 Levels in SH-SY5Y Cells}

Following treatment with acteoside or isoacteoside, culture media and SH-SY5Y cells were collected separately and the levels of $A \beta$ 1-40 therein were determined using human $A \beta$ 1-40 immunoassay kits (Invitrogen, Carlsbad, CA, USA). Experiments were performed according to the protocol of the manufacturer of the kits.

\subsubsection{Assessment of Cell-Free A $\beta$ 1-40 Degradation In Vitro}

The culture medium that contained the proteases to degrade $A \beta$ was collected and used for the cell-free assay of $A \beta$ degradation. Ten nanograms of $A \beta 1-40$ was added to $300 \mu \mathrm{L}$ culture medium that contained acteoside or isoacteoside, and incubated at $37^{\circ} \mathrm{C}$ for $24 \mathrm{~h}$. The remaining $\mathrm{A} \beta$ was then quantified using human $A \beta 1-40$ immunoassay kits.

\subsubsection{Assessment of $A \beta 1-42$ Oligomerization In Vitro}

A $\beta$ 1-42 $(100 \mu \mathrm{M})$ was dissolved in F-12 medium that contained acteoside or isoacteoside, and incubated at $4{ }^{\circ} \mathrm{C}$ for $24 \mathrm{~h}$ to accelerate $\mathrm{A} \beta$ oligomerization. The reaction solution was mixed with $5 \mu \mathrm{M} \mathrm{ThT}$, and was then incubated for $30 \mathrm{~min}$. The intensity of fluorescence at an emission wavelength of $485 \mathrm{~nm}$ was measured under excitation at a wavelength of $450 \mathrm{~nm}$.

\subsection{Statistical Analysis}

The data of passive avoidance response were analyzed by performing a Kruskal-Wallis non-parametric one-way analysis of variance, followed by Dunn's test. One-way analysis of variance (ANOVA) and then Scheff's test were applied to data concerning spatial performance, probe test, the ratio of amyloid deposition, the activities of AChE and MAO, the levels of central neurotransmitters and their metabolites, and cell viability and amyloidogenic test. Significant differences in all statistical evaluations were calculated using SPSS software (version 22, IBM, Armonk, NY, USA) and $p$-values $<0.05$ were considered significance.

\section{Conclusions}

Based on our results and those presented elsewhere [13,16,18,19,35], we suggest that acteoside and isoacteoside are potential therapeutic phenylethanoid glycosides for AD. The memory-improving mechanism of acteoside and isoacteoside involves reducing $A \beta$ deposition and $A \beta$ cytotoxicity by inhibiting $A \beta$ oligomerization through the catechol moiety [19] and promoting $A \beta$ degradation, and then reversing cortical cholinergic dysfunction, which includes the inhibition of AChE activity. Isoacteoside is more effective than acteoside with respect to amyloidogenesis and amyloid oligomerization, and it exhibits a different behavioral-improving pattern against $A \beta 1$ 1-42-induced behavioral dysfunction. In the future, molecular docking studies of acteoside and isoacteoside against amyloid protein should be conducted and the interaction between phenylethanoid glycosides and amyloid protein must be assayed.

Supplementary Materials: Supplementary materials can be found at www.mdpi.com/1422-0067/18/4/895/s1. Acknowledgments: We would like to thank the financial support of Institute for Information Industry 96-EC-17-A-20-I1-0049. We also thank Sinphar Pharmaceutical Co., Ltd. (I-Lan, Taiwan) for providing acteoside and isoacteoside.

Author Contributions: Chi-Rei Wu performed the in vivo experiments and analyzed the data; Young-Ji Shiao and Muh-Hwan Su performed the in vitro experiments and analyzed the data; Hang-Ching Lin isolated and identified these compounds; Chi-Rei Wu conceived, designed, supervised the study, drafted and revised the manuscript.

Conflicts of Interest: The authors declare no conflict of interest. 


\section{Abbreviations}

$\begin{array}{ll}\text { A } \beta & \text { Amyloid } \beta \text { peptide } \\ \text { Ach } & \text { Acetylcholine } \\ \text { AChE } & \text { Acetylcholinesterase } \\ \text { AD } & \text { Alzheimer's disease } \\ \text { APP } & \text { Amyloid precursor protein } \\ \text { BF } & \text { Basal forebrain } \\ \text { Ch } & \text { Choline } \\ \text { DA } & \text { Dopamine } \\ \text { MAO } & \text { Monoamine oxidase } \\ \text { MTT } & \text { 3-[4,5-dimethylthiazol-2-yl]-2,5-diphenyl-tetrazolium bromide } \\ \text { MWM } & \text { Morris water maze } \\ \text { NE } & \text { Norepinephrine } \\ \text { PBS } & \text { Phosphate buffer saline } \\ \text { ThT } & \text { Thioflavin T }\end{array}$

\section{References}

1. Hardy, J.; Selkoe, D.J. The amyloid hypothesis of Alzheimer's disease: Progress and problems on the road to therapeutics. Science 2002, 297, 353-356. [CrossRef] [PubMed]

2. Karran, E.; Mercken, M.; de Strooper, B. The amyloid cascade hypothesis for Alzheimer's disease: An appraisal for the development of therapeutics. Nat. Rev. Drug Discov. 2011, 10, 698-712. [CrossRef] [PubMed]

3. Querfurth, H.W.; LaFerla, F.M. Alzheimer's disease. N. Engl. J. Med. 2010, 362, 329-344. [CrossRef] [PubMed]

4. Li, L.; Tsao, R.; Liu, Z.; Liu, S.; Yang, R.; Young, J.C.; Zhu, H.; Deng, Z.; Xie, M.; Fu, Z. Isolation and purification of acteoside and isoacteoside from Plantago psyllium L. by high-speed counter-current chromatography. J. Chromatogr. A 2005, 1063, 161-169. [CrossRef] [PubMed]

5. Pettit, G.R.; Numata, A.; Takemura, T.; Ode, R.H.; Narula, A.S.; Schmidt, J.M.; Cragg, G.M.; Pase, C.P. Antineoplastic agents, 107. Isolation of acteoside and isoacteoside from Castilleja linariaefolia. J. Nat. Prod. 1990, 53, 456-458. [CrossRef] [PubMed]

6. Ohno, T.; Inoue, M.; Ogihara, Y.; Saracoglu, I. Antimetastatic activity of acteoside, a phenylethanoid glycoside. Biol. Pharm Bull. 2002, 25, 666-668. [CrossRef] [PubMed]

7. Chiou, W.F.; Lin, L.C.; Chen, C.F. Acteoside protects endothelial cells against free radical-induced oxidative stress. J. Pharm Pharmacol. 2004, 56, 743-748. [CrossRef] [PubMed]

8. Lee, K.J.; Woo, E.R.; Choi, C.Y.; Shin, D.W.; Lee, D.G.; You, H.J.; Jeong, H.G. Protective effect of acteoside on carbon tetrachloride-induced hepatotoxicity. Life Sci. 2004, 74, 1051-1064. [CrossRef] [PubMed]

9. Koo, K.A.; Kim, S.H.; Oh, T.H.; Kim, Y.C. Acteoside and its aglycones protect primary cultures of rat cortical cells from glutamate-induced excitotoxicity. Life Sci. 2006, 79, 709-716. [CrossRef] [PubMed]

10. Wang, H.; Xu, Y.; Yan, J.; Zhao, X.; Sun, X.; Zhang, Y.; Guo, J.; Zhu, C. Acteoside protects human neuroblastoma SH-SY5Y cells against $\beta$-amyloid-induced cell injury. Brain Res. 2009, 1283, 139-147. [CrossRef] [PubMed]

11. Yamada, P.; Iijima, R.; Han, J.; Shigemori, H.; Yokota, S.; Isoda, H. Inhibitory effect of acteoside isolated from Cistanche tubulosa on chemical mediator release and inflammatory cytokine production by RBL-2H3 and KU812 cells. Planta Med. 2010, 76, 1512-1518. [CrossRef] [PubMed]

12. Jing, W.; Chunhua, M.; Shumin, W. Effects of acteoside on lipopolysaccharide-induced inflammation in acute lung injury via regulation of NF-kB pathway in vivo and in vitro. Toxicol. Appl. Pharmacol. 2015, 285, 128-135. [CrossRef] [PubMed]

13. Lin, J.; Gao, L.; Huo, S.X.; Peng, X.M.; Wu, P.P.; Cai, L.M.; Yan, M. Effect of acteoside on learning and memory impairment induced by scopolamine in mice. China J. Chin. Mater. Med. 2012, 37, 2956-2959.

14. Xiong, L.; Mao, S.; Lu, B.; Yang, J.; Zhou, F.; Hu, Y.; Jiang, Y.; Shen, C.; Zhao, Y. Osmanthus fragrans flower extract and acteoside protect against D-galactose-induced aging in an ICR mouse model. J. Med. Food 2016, 19, 54-61. [CrossRef] [PubMed] 
15. Gao, L.; Peng, X.; Huo, S.; He, Y.; Yan, M. Acteoside enhances expression of neurotrophin-3 in brain tissues of subacute aging mice induced by D-galactose combined with aluminum trichloride. Chin. J. Cell. Mol. Immunol. 2014, 30, 1022-1025.

16. Peng, X.M.; Gao, L.; Huo, S.X.; Liu, X.M.; Yan, M. The mechanism of memory enhancement of acteoside (Verbascoside) in the senescent mouse model induced by a combination of D-gal and $\mathrm{AlCl}_{3}$. Phytother. Res. 2015, 29, 1137-1144. [CrossRef] [PubMed]

17. Gao, L.; Peng, X.M.; Huo, S.X.; Liu, X.M.; Yan, M. Memory enhancement of acteoside (Verbascoside) in a senescent mice model induced by a combination of D-gal and $\mathrm{AlCl}_{3}$. Phytother. Res. 2015, 29, 1131-1136. [CrossRef] [PubMed]

18. Wang, H.Q.; Xu, Y.X.; Zhu, C.Q. Upregulation of heme oxygenase-1 by acteoside through ERK and PI3 K/Akt pathway confer neuroprotection against $\beta$-amyloid-induced neurotoxicity. Neurotox. Res. 2012, 21 , 368-378. [CrossRef] [PubMed]

19. Kurisu, M.; Miyamae, Y.; Murakami, K.; Han, J.; Isoda, H.; Irie, K.; Shigemori, H. Inhibition of amyloid $\beta$ aggregation by acteoside, a phenylethanoid glycoside. Biosci. Biotechnol. Biochem. 2013, 77, 1329-1332. [CrossRef] [PubMed]

20. Myhrer, T. Neurotransmitter systems involved in learning and memory in the rat: A meta-analysis based on studies of four behavioral tasks. Brain Res. Rev. 2003, 41, 268-287. [CrossRef]

21. Itoh, A.; Nitta, A.; Nadai, M.; Nishimura, K.; Hirose, M.; Hasegawa, T.; Nabeshima, T. Dysfunction of cholinergic and dopaminergic neuronal systems in $\beta$-amyloid protein-Infused rats. J. Neurochem. 1996, 66, 1113-1117. [CrossRef] [PubMed]

22. Tran, M.H.; Yamada, K.; Nabeshima, T. Amyloid $\beta$-peptide induces cholinergic dysfunction and cognitive deficits: A minireview. Peptides 2002, 23, 1271-1283. [CrossRef]

23. Yamada, K.; Tanaka, T.; Mamiya, T.; Shiotani, T.; Kameyama, T.; Nabeshima, T. Improvement by nefiracetam of $\beta$-amyloid-(1-42)-induced learning and memory impairments in rats. Br. J. Pharmacol. 1999, 126, $235-244$. [CrossRef] [PubMed]

24. Wu, C.R.; Lin, H.C.; Su, M.H. Reversal by aqueous extracts of Cistanche tubulosa from behavioral deficits in Alzheimer's disease-like rat model: Relevance for amyloid deposition and central neurotransmitter function. BMC Complement. Altern. Med. 2014, 14, 202. [CrossRef] [PubMed]

25. Lee, K.Y.; Jeong, E.J.; Lee, H.S.; Kim, Y.C. Acteoside of Callicarpa dichotoma attenuates scopolamine-induced memory impairments. Biol. Pharm Bull. 2006, 29, 71-74. [CrossRef] [PubMed]

26. Arai, H.; Ichimiya, Y.; Kosaka, K.; Moroji, T.; Iizuka, R. Neurotransmitter changes in early- and late-onset Alzheimer-type dementia. Prog. Neuropsychopharmacol. Biol. Psychiatry 1992, 16, 883-890. [PubMed]

27. Gulyas, B.; Pavlova, E.; Kasa, P.; Gulya, K.; Bakota, L.; Varszegi, S.; Keller, E.; Horvath, M.C.; Nag, S.; Hermecz, I.; et al. Activated MAO-B in the brain of Alzheimer patients, demonstrated by ${ }^{11} \mathrm{C}$-L-deprenyl using whole hemisphere autoradiography. Neurochem. Int. 2011, 58, 60-68. [CrossRef] [PubMed]

28. Parihar, M.S.; Hemnani, T. Alzheimer's disease pathogenesis and therapeutic interventions. J. Clin. Neurosci. 2004, 11, 456-467. [CrossRef] [PubMed]

29. Kim, D.; Baik, S.H.; Kang, S.; Cho, S.W.; Bae, J.; Cha, M.Y.; Sailor, M.J.; Mook-Jung, I.; Ahn, K.H. Close correlation of monoamine oxidase activity with progress of Alzheimer's disease in mice, observed by in vivo two-photon imaging. ACS Cent. Sci. 2016, 2, 967-975. [CrossRef] [PubMed]

30. Nakamura, S.; Kawamata, T.; Akiguchi, I.; Kameyama, M.; Nakamura, N.; Kimura, H. Expression of monoamine oxidase B activity in astrocytes of senile plaques. Acta Neuropathol. 1990, 80, 419-425. [CrossRef] [PubMed]

31. Smale, G.; Nichols, N.R.; Brady, D.R.; Finch, C.E.; Horton, W.E., Jr. Evidence for apoptotic cell death in Alzheimer's disease. Exp. Neurol. 1995, 133, 225-230. [CrossRef] [PubMed]

32. Blanco, N.J.; Love, B.C.; Cooper, J.A.; McGeary, J.E.; Knopik, V.S.; Maddox, W.T. A frontal dopamine system for reflective exploratory behavior. Neurobiol. Learn. Mem. 2015, 123, 84-91. [CrossRef] [PubMed]

33. Young, J.W.; Kooistra, K.; Geyer, M.A. Dopamine receptor mediation of the exploratory/hyperactivity effects of modafinil. Neuropsychopharmacology 2011, 36, 1385-1396. [CrossRef] [PubMed]

34. Alttoa, A.; Seeman, P.; Koiv, K.; Eller, M.; Harro, J. Rats with persistently high exploratory activity have both higher extracellular dopamine levels and higher proportion of D2 (High) receptors in the striatum. Synapse 2009, 63, 443-446. [CrossRef] [PubMed] 
35. Bai, P.; Peng, X.M.; Gao, L.; Huo, S.X.; Zhao, P.P.; Yan, M. Study on protective effect of acteoside on cellular model of Alzheimer's disease induced by okadaic acid. China J. Chin. Mater. Med. 2013, 38, 1323-1326.

36. Pu, X.; Song, Z.; Li, Y.; Tu, P.; Li, H. Acteoside from Cistanche salsa inhibits apoptosis by 1-methyl-4phenylpyridinium ion in cerebellar granule neurons. Planta Med. 2003, 69, 65-66. [CrossRef] [PubMed]

37. Skaper, S.D. The neurotrophin family of neurotrophic factors: An overview. Methods Mol. Biol. 2012, 846, 1-12. [PubMed]

38. Korsching, S.; Auburger, G.; Heumann, R.; Scott, J.; Thoenen, H. Levels of nerve growth factor and its mRNA in the central nervous system of the rat correlate with cholinergic innervation. EMBO J. 1985, 4, 1389-1393. [PubMed]

39. Auld, D.S.; Mennicken, F.; Quirion, R. Nerve growth factor rapidly induces prolonged acetylcholine release from cultured basal forebrain neurons: Differentiation between neuromodulatory and neurotrophic influences. J. Neurosci. 2001, 21, 3375-3382. [PubMed]

40. Mufson, E.J.; Counts, S.E.; Perez, S.E.; Ginsberg, S.D. Cholinergic system during the progression of Alzheimer's disease: Therapeutic implications. Expert Rev. Neurother. 2008, 8, 1703-1718. [CrossRef] [PubMed]

41. Glowinski, J.; Iversen, L.L. Regional studies of catecholamines in the rat brain. I. The disposition of $\left[{ }^{3} \mathrm{H}\right]$ norepinephrine, $\left[{ }^{3} \mathrm{H}\right]$ dopamine and $\left[{ }^{3} \mathrm{H}\right]$ dopa in various regions of the brain. J. Neurochem. 1966, 13, 655-669. [CrossRef] [PubMed]

(C) 2017 by the authors. Licensee MDPI, Basel, Switzerland. This article is an open access article distributed under the terms and conditions of the Creative Commons Attribution (CC BY) license (http://creativecommons.org/licenses/by/4.0/). 